\begin{tabular}{|c|c|c|}
\hline & Mansoura University \\
Faculty of Engineering & Mansoura Engineering Journal & 0 \\
\hline
\end{tabular}

\title{
Dynamic Performance Enhancement of Vertical Wind Turbine Using Composite Blades Reinforced by Zinc-Oxide Nanoparticles
}

\author{
Khaled Khader, Shehab A. Mansour, Ibrahim M. El Fahham and Mamdoh Elimy
}

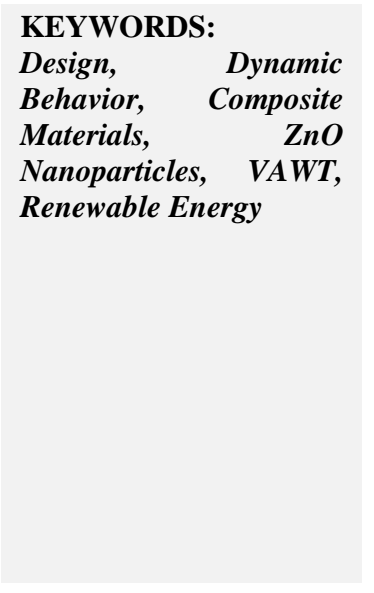

\begin{abstract}
The Performance of Vertical Axis Wind Turbine (VAWT) is highly dependent on its blades strength and stability. This paper is mainly dealing with enhancing the blades' structure of Vertical Axis Wind Turbine which is suitable for countries that have a moderate wind speed. The suggested improvement entails employing reinforced light composite blades using Zinc-Oxide (ZnO) nanoparticles (NPs) synthesized by the polymer-pyrolysis route. To assess the performance of the proposed design, a multistage Savonius blades prototype is built to realize the essential ultrasonic and vibration tests. Five different composite blades with different $\mathrm{ZnO}$ volume percentages are tested for assessing their values of the attenuation coefficient and the phase velocity and evaluating the composite material robustness. A wind tunnel is also used to evaluate the prototype power coefficient. Besides, the effect of the shift-angles between the different blades' stages on the turbine efficiency has been evaluated. The theoretical analysis and experimental results of the natural frequencies ensured that the proposed model can avoid the resonance scenarios through working at considerably high rotating speeds.
\end{abstract}

\section{INTRODUCTION}

$\mathrm{F}$ OSSIL fuels are the main effective conventional energy sources in modern industrial development. The economic, technical and environmental difficulties are the main critical problems that are slowing the countries' efforts to extract their needs from conventional energy sources like coal and oil. Furthermore, many countries are fronting severe difficulties related to growing their annual consumption of conventional energy sources. Moreover, the

Received: (4 August, 2020) - Revised: (17 September, 2020) - Accepted: (17 September, 2020)

Khaled Khader, Production Engineering and Mechanical Design Department, Faculty of Engineering, Menoufia University, Shebin El-kom, Menoufia, Egypt (e-mail: khkhm62@hotmail.com)

Shehab A. MAnsour, Basic Engineering Science Department, Faculty of Engineering, Menoufia University, Shebin El-Kom, Egypt (e-mail: shehabmansour@yahoo.com) rapid depletion of fossil fuels is the major concern of the industrial countries' over the last decades. Fortunately, the rapid depletion problem can be resolved using clean and cheap renewable resources like wind and solar energy. These renewable energy sources can compensate for the shortage between the growing demand and the available traditional types of energies in countries that are suffering from insufficient traditional energies. Apparently, renewable energy sources can be used in many applications which include generating cheap electricity for the deprived communities in the desert areas in addition to powering the desalination plants for producing the

Corresponding Author: Ibrahim M. El Fahham, * Mechanical Engineering Department, Faculty of Engineering, Alexandria University, Alexandria, Egypt.(e-mail: ibrahim.elfahham@alexu.edu.eg)

Mamdoh Elimy, Production Engineering and Mechanical Design Department, Faculty of Engineering, Menoufia University, Shebin El-kom, Menoufia,Egypt (e-mail: mamdouhelimi2017@gmail.com) 
needed drinking clean water. As examples, the wind turbines have been used in wind farms to produce cheap electricity [1, 2]. Moreover, the desalination plants near the seas beach can be powered using solar or wind energy [3-5]. Also, a widespread scientific study in this regard was presented by Ramkissoon et al. [6] to assess the renewable energy sources' potential development in operating a water desalination plant in Trinidad. Unfortunately, on the other hand a few communities in some areas around the world, as on a certain island in Greece, are resisting the renewable energy usage in their regions as discussed by Kaldellis [7]. Generally, there are many research work challenges accompanied by the different renewable energy systems which are developed for generating the needed energies [8,9].

Currently, wind energy has attracted several researchers as one of the important domains of renewable resources in addition to its encouraging opportunities for application in several fields. Most of the research work in the renewable energy field is focused on determining the proper approaches for energy generation in a particular scenario [10] or to improve the efficiency of a certain system [11].

Commonly, two types of wind turbines can be used to convert wind energy to power generation. Those two main types are the Horizontal and the Vertical Axis Wind Turbines known as HAWT and VAWT. Intensive studies devoted to compare HAWT and VAWT performance at typical wind speed range are presented in [12-14].

Generally, HAWT is only economically valuable at steady high-speed wind as discussed in [13-16]. Furthermore, VAWT preserves its performance independently of wind direction. Also, VAWT has a simplified construction design and it can efficiently work via simple maintenance in addition to low cost of operation. Therefore, VAWT is appropriate for using it as dispersed units in rural communities. Moreover, new wind turbines' designs for generating cheap electricity, such as the floating offshore wind turbine were presented in [1, 17-18]. Furthermore, offshore VAWT can be used in compressed air energy storage system $[19,20]$. The common shape of the VAWT blades that can be effectively employed is the Savonius type blades. Moreover, different Savonius blades' shape optimization of VAWT was presented in [21].

The VAWT performance analyses in addition to the flow field assessment are focused by many researchers [22-24]. Some research works were focused on manufacturing appropriate prototypes, which were experimentally assessed in wind tunnels, to investigate their performance [25-28]. Moreover, widespread studies were concerned with the computational fluid dynamics (CFD) usage [29-31]. These studies were dealing with the wind turbine simulations by focusing on the aerodynamics and air flow. Otherwise, many research works were focused on the use of composites and polymer based materials in VAWT blades. As examples, an intensive study for studying the feasibility of using fiberreinforced polymer composite in VAWT blades was presented by Zhong-Jia et al. [32]. It was concluded that the light blade weight resulting from the low density of the blades composite structure could significantly enhance the efficiency and the performance of the wind turbine which has composite blades. Furthermore, a concentrated study dealing with Finite Element (FE) analysis of a composite VAWT blade was introduced by Hameed et al. [33] for studying the effect of the centrifugal forces on the deflection of wind turbine's blade. Moreover, Lin et al. [34] presented a structural analysis study considering the ultimate strength analysis of VAWT composite blades to determine the fatigue-critical locations of the turbine's blades. Also, a widespread study dealing with composite blades' fatigue of large Darrieus VAWT was introduced by Kumar et al. [35]. They inferred that most of the turbine failures are related to the blade's fatigue due to constantly aerodynamic force variations on each revolution. The dipping of inorganic nanoparticles (NPs) into epoxy not only improves their mechanical properties, but also enables to overcome their shortcomings from the point of view of some practical usages by enhancing their flame-retardant, thermal stabilization and other properties [36].

Savonius type wind turbines reduced efficiency was considered by many research works. In order to increase the output torque, modified blades and rotor designs were adapted through the optimization of blade profile and using obstacle shielding to eliminate the negative torque of the non-active side. El-Askary et al. [37] studied the performance of a twisted Savonius wind blade rotor with a modified profiles at various overlap ratios and aspect ratios. Whereas Mohamed et al. [38] achieve their objective through optimizing the position of an obstacle that shields the returning blade of a Savonius wind turbine. This optimization process led to a considerable improvement of the power coefficient in the range of $27 \%$. Khader and Nada [39] also used a rotating shield to orient the inlet flow and used crank-crank mechanism to reorient his model blades to improve its performance.

The objective of this research work is to improve the dynamic performance of VAWT composite blades' structure by using reinforced blades composite material with Zinc-Oxide (ZnO) Nanoparticles. To evaluate our goal, a VAWT prototype of multistage Savonius composite blades is manufactured to perform necessary vibration and ultrasonic tests and assess the prototype performance. The theoretical and experimental natural frequencies of the prototype are evaluated to ensure that the proposed model is capable of rotating at considerably high speeds without being exposed to resonance problems. On the other hand, the effect of changing the shift-angle between the turbine blades stages (layers) on the prototype efficiency was assessed.

\section{GUIDELINES SYSTEM MODELING}

In this section, a comprehensive system modeling of a four blades Savonius vertical wind generator is presented for assessing the proposed model power coefficient along with the natural frequencies and mode shapes. Also, the system modeling is considering the ultrasonic diagnostics. First, a 
mathematical model is presented for evaluating the power coefficient of the model that is provided with one stage (layer) of four Savonius blades. Then, system modeling is obtained for evaluating the natural frequencies and mode shapes of the model. Finally, the ultrasonic diagnostics details are presented.

\section{A. Mathematical Model for the Proposed Savonius VAWT Power Coefficient}

The vertical axis wind turbine which is provided with four Savonius blades is shown in Fig. 1.

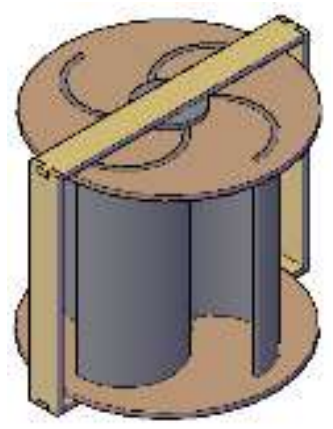

Fig. 1. Four Savonius blades' VAWT

With the assumption that the whole wind energy hitting the mating blade surface area is consumed to move the blades, the theoretical maximum power $\left(P_{\max }\right)$ can be expressed as follows; $P_{\max }=0.5 \rho A V^{3}$

where: $(\rho)$ is the air density, $(V)$ is the wind velocity and $(A)$ is the mating blades surface area. The area of the blade is the product of the blade height $(H)$ with its width $(W)$.

The instantaneous power $\left(P_{i}\right)$ of this turbine depends on the effective blades area facing the wind as shown in Fig. 2. This power can be expressed as follows;

$P_{i}=0.5 \rho w_{e} H V^{3}$

where $\left(w_{\mathrm{e}}\right)$ is the apparent width of the blades. This width $\left(w_{\mathrm{e}}=\sum w_{e i, i=1,2, \ldots}\right)$ differs with respect to the blade angle $(\theta)$. The previous relation of the turbine power can be rewritten as follows;

$P_{i}=K w_{e}$

where the value of $(K)$ can be expressed as;

$K=0.5 \rho H V^{3}$

Therefore, the power $(P)$ of the proposed four Savonius blades turbine can be expressed through its quasi-active revolution as;

$P=\frac{K}{2 \pi} \int_{\theta=0}^{\pi} w_{e} d \theta$

From the design presented in Fig. 2, it can be observed that at most three blades can be in the active side. Therefore, the power $(P)$ can be calculated within three different intervals through the half active revolution which comes from the movement of the first, second and fourth blade, respectively. This power depends on the blade width $\left(w_{e j}, j=1,2\right.$ and 3$)$ of the three intervals, respectively. The calculated power $(P)$ within the half active revolution can be considered as;

$P=\frac{K}{2 \pi} \sum_{j=1}^{j=3} \int_{\theta=0}^{\pi} w_{e j} d \theta$

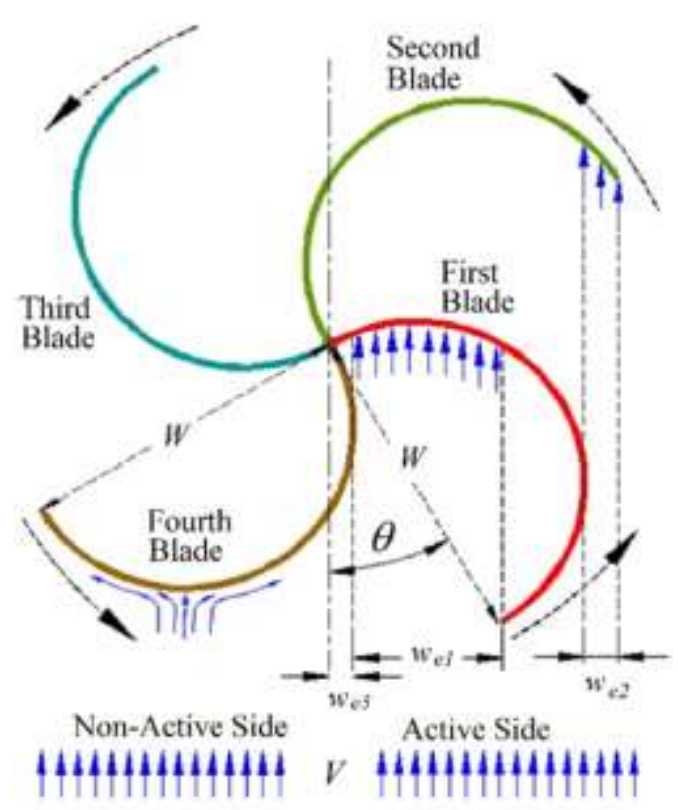

Fig. 2. Orientation of four Savonius blades' VAWT

At the beginning, the first interval which is computed from the first blade begins from $(\theta=0)$ till $\left(\theta=\theta_{1 f}\right)$. The width $\left(w_{e 1}\right)$ of the first blade exposed to the wind starts from a value equals zero. Then this exposed width increases till it reaches its maximum value when $\left(\theta=\theta_{1 x}\right)$. After that, $\left(w_{e 1}\right)$ decreases again to reach a value equals zero at the end of this interval when $\left(\theta=\theta_{1 f}\right)$. This width can be expressed as follows;

$w_{e 1}=W\left(\sin \theta+\frac{1}{2} \cos \theta-\frac{1}{2}\right)$

Where;

$\theta_{1 f}=\pi-\sin ^{-1}(0.8)$, and $\theta_{1 f} \geq\left(\frac{\pi}{2}\right)$

$\theta_{1 x}=\tan ^{-1}(2), \theta_{1 x}<\left(\frac{\pi}{2}\right)$

While the second interval, which is associated with the motion of the second blade, begins from $(\theta=0)$ till $\left(\theta=\theta_{2 f}\right)$. At the beginning of this interval, the second blade starts to move with its maximum exposed width equals to $(0.5 \mathrm{~W})$, then, this exposed width decreases till value equals zero by the end of this interval at $\left(\theta=\theta_{2 f}\right)$. This exposed width $\left(w_{e 2}\right)$ can be expressed as;

$w_{e 2}=W\left(\cos \theta-\frac{1}{2} \sin \theta-\frac{1}{2}\right)$

Where;

$\theta_{2 f}=\sin ^{-1}(0.6)$, and $0<\theta_{2 f} \leq\left(\frac{\pi}{2}\right)$

Finally, the third interval, which is owing to the motion of the fourth blade, starts at $(\theta=0.5 \pi)$ and it finishes at $(\theta=\pi)$. The width $\left(w_{e 3}\right)$ of the fourth blade also begins from a value equals zero when $(\theta=0.5 \pi)$, and then this exposed width increases till it reaches its maximum value when $\left(\theta=\theta_{4 x}\right)$. After that, $\left(w_{e 3}\right)$ decreases again to reach value equals $(0.5 W)$ at the 
end of this interval when $(\theta=\pi)$. This width can be expressed as;

$w_{e 3}=W\left(-\cos \theta+\frac{1}{2} \sin \theta-\frac{1}{2}\right)$,

$\theta_{4 x}=\pi-\tan ^{-1}(0.5), \theta_{4 x}>\left(\frac{\pi}{2}\right)$

The relation between the relative width $\left(w_{e i} / W\right)$ and the rotating angle $(\theta)$ is illustrated in Fig. 3. The relative width is the ratio between the exposed width of each blade $\left(w_{e i}, j=1,2\right.$ and 3 ) and the blade width $(W)$. Furthermore, the relation between the summation of the exposed blades width $\left(w_{e i}, j=1,2\right.$ and 3 ) divided by $(W)$, against the angle $(\theta)$ is shown in Fig. 4.

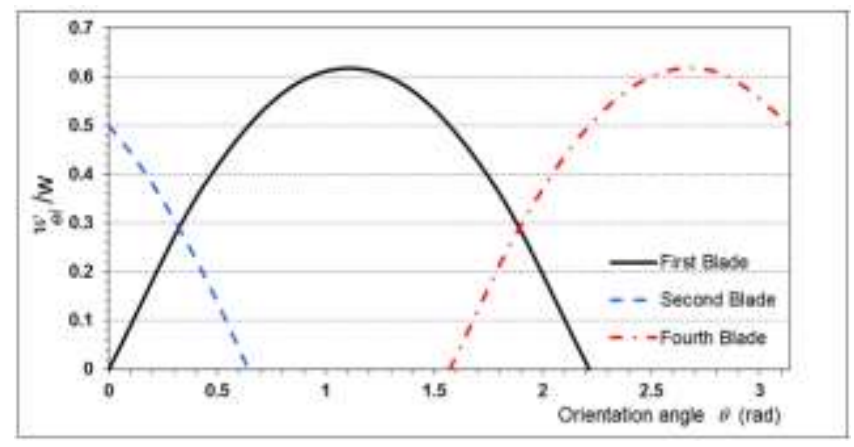

Fig. 3. The relative width of the first, second and fourth blade

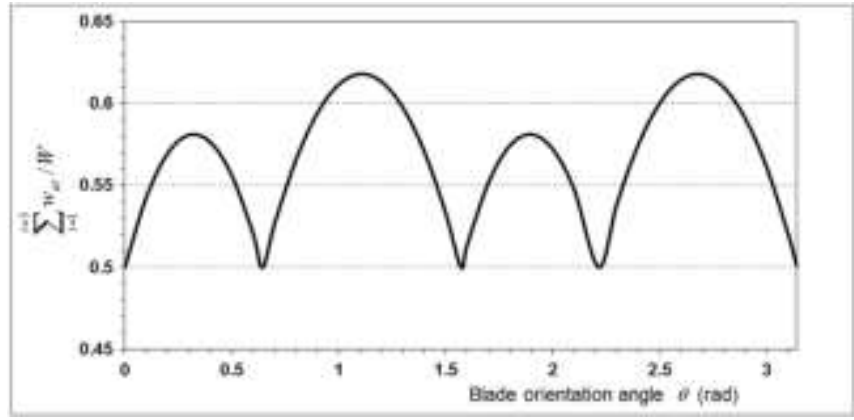

Fig. 4. The summation of the exposed width

Thus, the power $(P)$ from the half active revolution, attained from the summation of each blade power $\left(P=P_{s 1}+P_{s 2}+P_{s 3}\right)$, can be expressed as;

$$
\begin{aligned}
& P_{s 1}=\frac{W K}{2 \pi} \int_{\theta=0}^{\theta_{11}}\left(\sin \theta+\frac{1}{2} \cos \theta-\frac{1}{2}\right) d \theta \\
& P_{s 2}=\frac{W K}{2 \pi} \int_{\theta=0}^{\theta_{2 f}}\left(\cos \theta-\frac{1}{2} \sin \theta-\frac{1}{2}\right) d \theta \\
& P_{s 3}=\frac{W K}{2 \pi} \int_{\theta=0.5 \pi}^{\pi}\left(-\cos \theta+\frac{1}{2} \sin \theta-\frac{1}{2}\right) d \theta
\end{aligned}
$$

Therefore, the preceding three equations can be computed to evaluate the total power from the half active revolution of the proposed model. And $(P)$ can be calculated from;

$P=\frac{W K}{2 \pi} \sum_{j=1}^{j=3} C_{j}$

where the values of $\left(C_{j}, j=1,2\right.$ and 3$)$ can be formulated as follows;
$C_{1}=-\left(\cos \theta_{1 f}-1\right)+\frac{1}{2} \sin \theta_{1 f}-\frac{1}{2} \theta_{1 f}$

$C_{2}=\sin \theta_{2 f}+\frac{1}{2}\left(\cos \theta_{2 f}-1\right)-\frac{1}{2} \theta_{2 f}$

$C_{3}=\frac{6-\pi}{4}$

Generally, the total power generated from the whole revolution is the double of the half active revolution power. Accordingly, the power coefficient $\left(C_{T}\right)$ of the proposed model with four Savonius blades can be expressed as;

$C_{T}=\left(\frac{2 W K}{2 \pi} \sum_{j=1}^{3} C_{j}\right)\left(\frac{1}{0.5 \rho A_{s} V^{3}}\right)$

where $\left(A_{s}\right)$ is the exposed area of the four Savonius blades model $\left(A_{s}=2 W H\right)$. Consequently, the theoretical power coefficient $\left(C_{T}\right)$ of the four Savonius blades model can be computed from;

$C_{T}=\frac{1}{2 \pi} \sum_{j=1}^{3} C_{j}$

Performing all the previous calculation, it has been found that the theoretical power coefficient $\left(C_{T}\right)$ of the four Savonius blades model equals to $(0.2843)$. It is to note that the effect of non-active side of the blades is expected to be in the range of $20 \%$ [38]. But it is not included in the calculation since the model adopted the obstacle shielding mechanism.

\section{B. Finite Element and Natural Frequency Analysis of the Proposed Model}

Enhancing the VAWT performance is the main concern of the wind energy field's researchers. In this regard, the Finite Element (FE) analysis can be applied as an effective tool through modeling the VAWT [40]. Furthermore, the usage of FE for analyzing the VAWT performance can assess its natural frequencies and mode shapes. Hence, the danger of sudden collapse in addition to resonance scenarios can be avoided through running the turbine with the appropriate rotating speeds far from the speeds which can cause resonance [41]. Intensive research work is introduced in [42], which deals with the dynamic behavior of VAWT structure using the numerical simulation via FE in addition to ANSYS software.

To assess the Eigenvalues of multi-degrees of freedom systems considering only the free vibrations and ignoring damping, the equation of the system motion can be written as follows [43];

$[M]\{\ddot{\mathrm{u}}\}+[K]\{\mathrm{u}\}=\{0\}$

where $\{\mathrm{u}\}$ denotes the Eigenvectors, $[M]$ is the mass matrix, and $[K]$ denotes the stiffness matrix.

The following equation can be formulated as follows;

$\left([K]-\omega^{2}[M]\right)\{\mathrm{u}\}=\{0\}$, where $\mathrm{u}=\mathrm{U} \sin (\omega \mathrm{t})$

where $(\omega)$ is the angular frequency which it is equal to the square roots of $(K / M)$ and is denoted Eigenvalues. Moreover, $(f)$ is the structure's circular natural frequencies in cycles per second which can be evaluated as follows;

$f=\frac{\omega}{2 \pi}$ 
Here, the eigenvectors $\{\mathrm{u}\}_{i}$ can be evaluated using ANSYS software for representing the mode shape when the VAWT blades vibrate with $f_{i}$, where $i=1,2,3, \ldots, n$.

Numerical modal analysis can be created dealing with (FE) for the multi-stage model which is shown in Fig. 5, using ANSYS software. This model is implemented to get the model natural frequencies and mode shapes. Here, the arrangement and (FE) mesh refinement of the model contact elements are one of the main effective analysis parameters for getting accurate results. This arrangement and mesh refinement of the model contact elements are shown in Fig. 6.

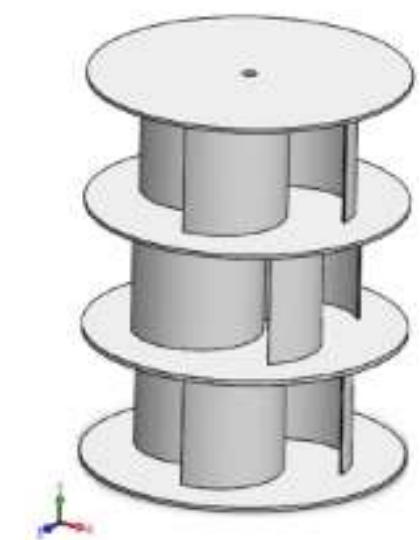

Fig. 5. Multi-stage Savonius type model

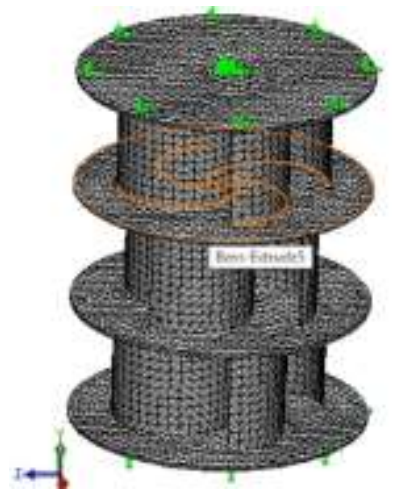

Fig. 6. Arrangement and mesh refinement of the model contact elements

\section{Ultrasonic Diagnostic of the Blades}

The attenuation coefficient and the phase velocity are important parameters which can be calculated to assess the composite material robustness [44-46]. Moreover, the magnetostractive pulse-echo technique can be effectively used for evaluating the attenuation coefficient $(\zeta)$ and the phase velocity $\left(C_{p}\right)$ as discussed in $[47,48]$. The attenuation coefficient $(\zeta)$ and the phase velocity $\left(C_{p}\right)$ in addition to the dynamic Young's modulus $\left(E_{\mathrm{d}}\right)$ can be calculated using the following relations as in $[47,48]$;

$$
\begin{aligned}
& \zeta=\left(\frac{-20}{2(m-n) L}\right) \log \left(\frac{A_{m}}{A_{n}}\right) \\
& C_{p}=\frac{2 L}{t} \\
& E_{d}=\rho C_{p}^{2}
\end{aligned}
$$

where $A_{\mathrm{m}}$ and $A_{\mathrm{n}}$ are the maximum amplitude (voltage) of $m^{\text {th }}$ and $n^{\text {th }}$ pulse echoes, respectively. Also, $(L)$ is the wire and specimen length. Besides, $(t)$ is the time and $(\rho)$ is the denoted mass density.

\section{PROTOTYPE BUILDING AND TESTING}

An appropriate prototype is built for assessing the dynamic performance enhancement of the proposed model. This prototype consists of three stages (layers) of four Savonius blades. The blades of this prototype are fabricated from a composite materials reinforced by zinc-oxide nanoparticles.

Firstly, specific scientific experimental procedures are employed for preparing the required zinc-oxide nanoparticles to reinforce the proposed model composite blades. These prepared nanoparticles can be added through forming the model blades. Finally, the required vibration tests in addition to the ultrasonic diagnostics for the proposed prototype are performed. The details of the procedures that have been followed for building and testing the prototype are explained in the following subsections;

\section{A. Synthetization of the Zinc-Oxide Nanoparticles and Fabrication of Blades}

The polymer-pyrolysis route has been used to synthesize $\mathrm{ZnO}$ NPs. Zinc acetate dehydrate $\left(\mathrm{Zn}\left(\mathrm{CH}_{3} \mathrm{COO}\right)_{2} 2 \mathrm{H}_{2} \mathrm{O}\right.$, Sigma), acrylic acid $\left(\mathrm{CH}_{2}=\mathrm{CHCOOH}\right.$, Merck Millpore $)$ and ammonium persulfate (APS) have been used in the synthesization route without additional purification. The used synthetic route has been reported elsewhere $[49,50]$ with modification in the used quantity of the used precursors. In the typical route, $0.6 \mathrm{M}$ of $\mathrm{Zn}\left(\mathrm{CH}_{3} \mathrm{COO}\right)_{2}$ was dissolved in $30 \mathrm{~g}$ of acrylic acid (AC) aqueous solution (AC: distilled water $=70$ : $30 \mathrm{wt} . \%)$ at room temperature. After a complete dissolving of the Zinc salt, $1.5 \mathrm{~g}$ from APS aqueous solution at $5 \mathrm{wt} . \%$ concentration was added to the prepared Zinc acetate-AC solution. Then, the temperature of the solution raised and maintained at around $75{ }^{\circ} \mathrm{C}$ for $45 \mathrm{~min}$. The formation of polyacrylate salt was observed after such time of heating. The formed polyacrylate salt was dried at $250{ }^{\circ} \mathrm{C}$ for $2 \mathrm{~h}$. Thereafter, the dried polyacrylate was calcined at $600{ }^{\circ} \mathrm{C}$ for 2 hours in the air to get $\mathrm{ZnO}$ nanoparticle powder. The obtained powder is fine with off white color as typical ZnO NPs.

The prepared $\mathrm{ZnO}$ nanoparticle powder is mixed and stirred in the epoxy at the room temperature for fabricating the composite blades. Five different composite blades are fabricated using five different volume percentages of $\mathrm{ZnO}$ nanoparticle $(0 \%, 0.1 \%, 0.3 \%, 0.5 \%$, and $0.7 \%)$. These manufactured blades of one stage of the proposed model are shown in Fig. 7. The composite blades are manually fabricated by adding $\mathrm{ZnO}$ NPs to polyester. A bidirectional fabric form is used through fabricating the blades in PVC dies. These dies are half cylinders' PVC tubes that have $150 \mathrm{~mm}$ diameters and 150 $\mathrm{mm}$ length in all stages. The turbine blades have a shift distance $20 \mathrm{~mm}$ to outside between each other with no overlap. The turbine rotor dimensions were $450 \mathrm{~mm} \times 280 \mathrm{~mm}$. 


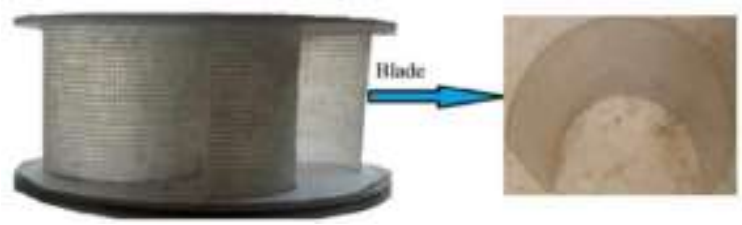

Fig. 7. The manufactured VAWT composite blade

\section{B. Characterization}

The XRPhillips X'pert diffractometer of type MPD3040 was used in the examination of the crystal structure of the synthesized. The used monochromatic source of $\mathrm{X}$-ray is $\mathrm{CuK}_{\alpha}$ source with wavelength $(\lambda)=1540.6 \AA$. The X-ray diffraction (XRD) pattern was recorded using a step-scan mode through $2 \theta$ range from $20^{\circ}$ to $80^{\circ}$ with a step size of $0.02^{\circ}$. Also, the morphology of the synthesized particles was characterized using high resolution transmission electron microscope (HRTEM) of type JEM-2100. The morphology of the fabricated epoxy/ZnO nanocomposites was characterized using fieldemission scanning electron microscope (FE-SEM, Quanta FEJ20).

\section{Structure and Morphology Characterization of $\mathrm{ZnO}$ Nanoparticles}

The recorded XRD pattern of the synthesized $\mathrm{ZnO}$ sample is shown in Fig. 8. The obtained diffraction peaks reveal the formation of $\mathrm{ZnO}$ with a wurtzite structure according to standard data of card (no. JCPDS-36-1451). Moreover, the calculated lattice constants are $c=3.247 \AA$ and $a=5.199 \AA$ that are in well agreement with those specified in the standard data $(a=3.249 \AA \& \quad c=5.206 \AA$ ) of card (no. JCPDS-36-1451). The mean value of the strain $(\varepsilon)$ was calculated according to the following relation;

$$
\varepsilon=\frac{c-c_{0}}{c_{0}} \times 100 \%
$$

where: $c_{0}$ is the lattice constant of the unstrained $\mathrm{ZnO}$ bulk $(5.206 \AA)$ [51]. The calculated value of $(\varepsilon)$ from the previous equation is found to be $-11.5 \times 10^{-4} \%$. This small negative value refers to the compressive limited strain in the crystal lattice. The crystallite size $(D)$ of the synthesized $\mathrm{ZnO}$ sample was estimated from line broadening of the highest intensities for the preferred plane orientation $(h k l)$ at (100), (002) and (101) using Scherrer formula [52] as follows;

$$
D=\frac{0.9 \lambda}{\beta_{h k l} \cos \theta_{k h l}}
$$

where: $\left(\beta_{h k l}\right)$ is the full-width at half maximum (FWHM) of the diffraction peak, $\left(\theta_{h k l}\right)$ is the Bragg angle at $(h k l)$ plane, and $(\lambda)$ is the wavelength of the used X-ray source. The estimated values of $(D)$ using Scherrer's equation for the preferred plane orientations (100), (002) and (101) are 43, 43.6 and $41.8 \mathrm{~nm}$, respectively. Such values emerge that the synthesized $\mathrm{ZnO}$ powder is nanostructured with close size in most preferred orientations.

The HRTEM micrographs of the investigated sample are shown in Fig. 9. The micrographs emerge the formation of welldefined nanoparticles with agglomerated structure. The obtained shape of the particles is almost hexagonal nanoparticles with average particle size $\sim 70 \mathrm{~nm}$. Moreover, Fig. 10 shows the micrograph image of epoxy/ZnO nanocomposite sample with $0.3 \mathrm{vol} . \% \mathrm{ZnO}$ nanoparticles as an example of the investigated epoxy nanocomposites. The yellow rectangular frames in such a figure refer to $\mathrm{ZnO}$ NPs distribution sites. As shown from such a figure, there is good dispersion of the NPs nanoparticles throughout the epoxy that is indicating a reasonable interaction between $\mathrm{ZnO}$ NPs and epoxy.

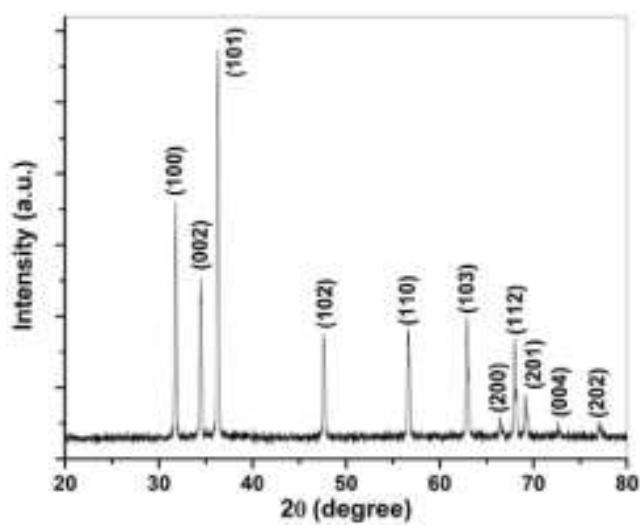

Fig. 8. XRD pattern of the synthesized $\mathrm{ZnO}$ sample
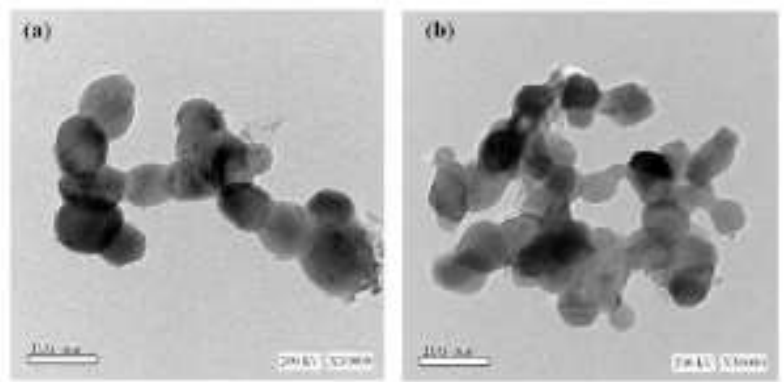

Fig. 9. TEM micrographs of the synthesized $\mathrm{ZnO}$ sample

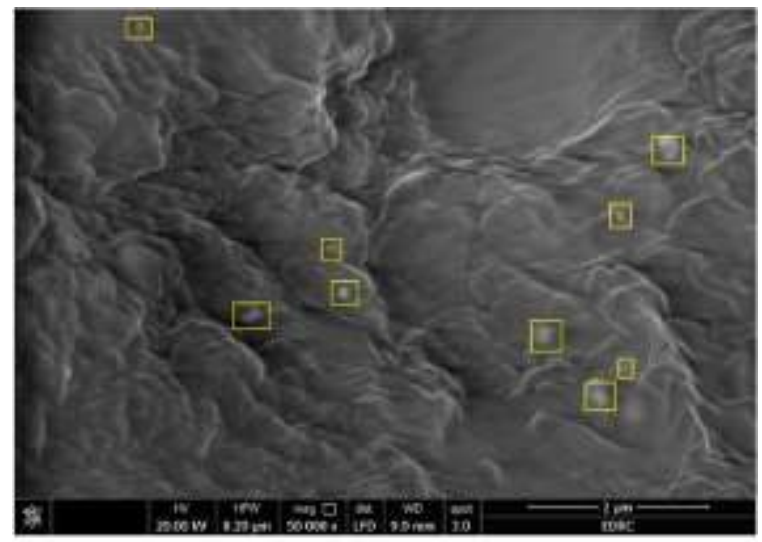

Fig. 10. FE-SEM micrograph of epoxy/ 0.3 vol.\% $\mathrm{ZnO}$ nanocomposite with $50000 \times$ magnification and $2-\mu \mathrm{m}$ scale

\section{The Proposed Prototype Building}

A suitable prototype is built for assessing the dynamic performance enhancement of the proposed Savonius type model. This prototype is shown in Fig. 11, which consists of three stages (layers) of composite blades. The composite blades of this prototype are manufactured using the prepared zinc- 
oxide nanoparticles. Each stage of the composite blades contains four Savonius blades which are arranged and fixed between two wooden disks. Moreover, the middle blades' stage can be adjusted with a different shift angle related to the other two stages. An accurate three-dimensional mechanical design of the proposed prototype has been created using SolidWorks Software [53]. Therefore, the required prototype fabricated to facilitate the required tests to compare the experimental results with that of the theoretical analysis.

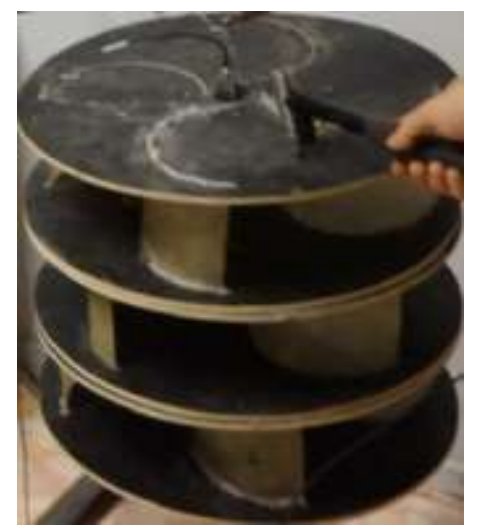

Fig. 11. Three stages composite blades of the prototype

\section{E. Vibration Tests}

The prototype experimental vibration tests were performed to investigate the frequency response. These tests accomplished using B\&K-tri-axial piezoelectric (type-4506) and B\&K-data acquisition (type 3160 ) which is connected with the computing laptop as shown in Fig. 12.

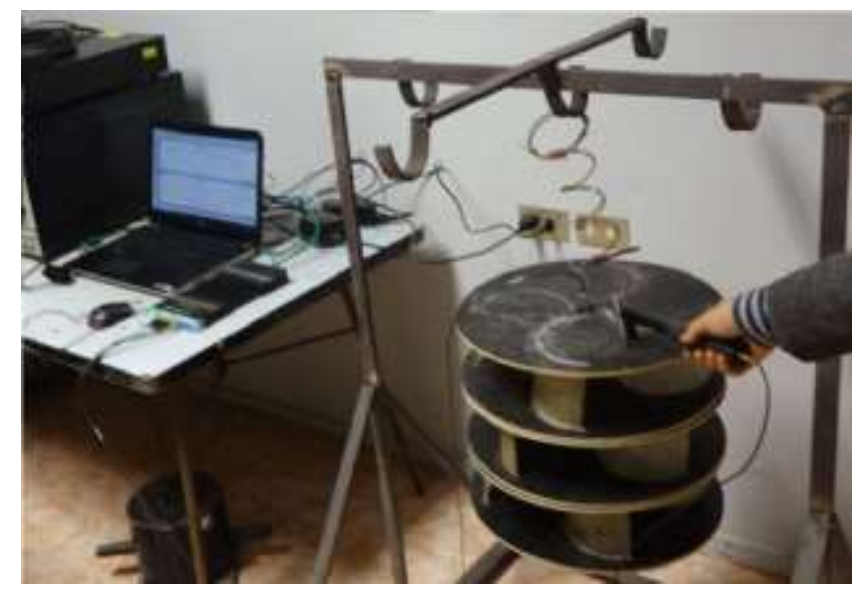

Fig. 12. Vibration tests of the prototype

\section{F. Ultrasonic Diagnostic Test}

The significant parameters as the attenuation coefficient in addition to phase velocity can be evaluated using the ultrasonic test arrangement which is shown in Fig. 13, for assessing the proposed model blade material robustness. This arrangement can be used for obtaining the specimens' longitudinal modes using the resonance frequency spectra.

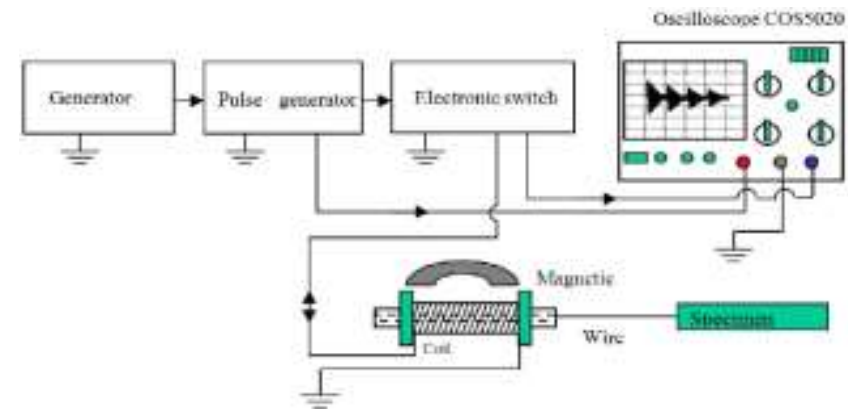

Fig. 13. Schematic diagram of the ultrasonic test arrangement

Moreover, a general burst of mechanical oscillation can excite the tested bonded composite elements along their main lengths with the specific natural frequency or at one of the harmonic frequencies of the specimens.

\section{G. Wind Tunnel Test}

To evaluate the power coefficient, the prototype was tested using a wind tunnel having a maximum wind speed of $12 \mathrm{~m} / \mathrm{s}$ at outlet. The wind tunnel shown in Fig. 14 has a length of 1500 $\mathrm{mm}$ with a square outlet $(450 \times 450 \mathrm{~mm})$.

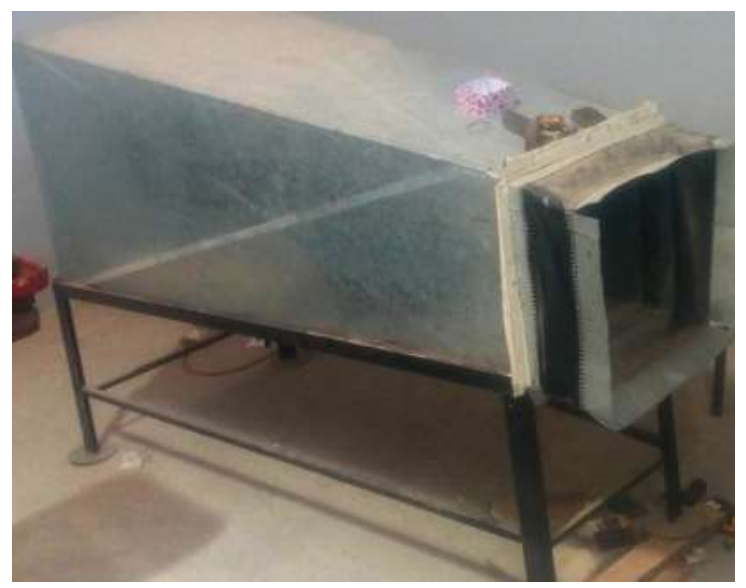

Fig. 14. Wind tunnel used for the evaluation of the power coefficient

To evaluate the power coefficient, a suitable resistance coupling torque was applied around an appropriate pulley which was mounted with the turbine's rotating shaft. Whereas the load was evaluated using different weights, rough rope and digital scale. Meanwhile, the corresponding angular speed of the turbine was measured using Digital Laser Photo Tachometer. Therefore, the measured power is the factor of the resistance torque and the corresponding measured angular speed.

\section{RESULTS AND DISCUSSIONS}

The ultrasonic diagnostics tests are performed dealing with five different specimens of the composite blades to measure the values of $(\zeta)$ and $\left(C_{p}\right)$ in addition to $\left(E_{d}\right)$ considering the first two echoes. These values are listed in Table 1 for five different specimens have volume percentages of $\mathrm{ZnO}$ nanoparticle $(0 \%$, $0.1 \%, 0.3 \%, 0.5 \%$, and $0.7 \%)$. The obtained values indicated that the values of $\left(C_{p}\right.$ and $\left.E_{d}\right)$ have an increasing trend associated with the increasing rate of the $\mathrm{ZnO}$ volume 
percentage. On the other hand, $(\zeta)$ has opposite trend. The maximum values of $\left(C_{p}\right.$ and $\left.E_{d}\right)$ in addition to the minimum value $(\zeta)$ are corresponding to the $\mathrm{ZnO}$ volume percentage equals $0.7 \%$, where increasing the volume percentage of $\mathrm{ZnO}$ resists the wave propagation path in the specimen. Moreover, the specimen of zero $\mathrm{ZnO}$ volume percentage has the highest value of the attenuation coefficient. This is related to the dissipation energy and damping effects via $\mathrm{ZnO}$ NPs. These damping effects may be related to the viscoelastic nature of matrix in addition to fiber materials as well as viscoelastic damping at large amplitudes of vibration. Also, the frictional damping effect can happen due to slipping in unbound regions.

TABLE 1

Values of $(\zeta),\left(C_{p}\right)$ and $\left(E_{d}\right)$ for different $\mathrm{ZnO}$ volume percentages

\begin{tabular}{c||c||c||c} 
Volume $\%$ of $\mathrm{ZnO}$ & $\zeta$ & $\mathrm{C}_{\mathrm{p}}[\mathrm{m} / \mathrm{s}]$ & $\mathrm{E}_{\mathrm{d}}[\mathrm{GPa}]$ \\
\hline 0 & 0.00913 & 3337.3 & 9.08 \\
\hline 0.1 & 0.00725 & 3635.3 & 12.45 \\
\hline 0.3 & 0.00526 & 4050.4 & 17.26 \\
\hline 0.5 & 0.00343 & 4403.5 & 20.15 \\
\hline 0.7 & 0.00201 & 4981.9 & 24.69
\end{tabular}

The composite blades of the tested prototype are fabricated using a volume percentage of $\mathrm{ZnO}$ NPs equal to $0.3 \%$. Here, this $\mathrm{ZnO}$ volume percentage is selected as a moderate value with reasonable manufacturing costs.

The power coefficient of this model is evaluated experimentally by evaluating the rotational speed and the corresponding torque at different wind speeds $(V \mathrm{~m} / \mathrm{s})$. The corresponding power can be computed as the product of the torque with the equivalent angular velocity. Hence, the experimental power coefficient is calculated by dividing the computed power by $\left(0.5 \rho A_{s} V^{3}\right.$, where $\left.A_{s}=2 W H\right)$. First, the experimental power coefficient was evaluated at seven different shift-angle of the middle blades layer related to the other two layers at a wind speed equals $(9 \mathrm{~m} / \mathrm{s})$, for assessing the effect of changing the shift-angle on the efficiency of the prototype. The relation between the shift-angle and the experimental power coefficients is shown in Fig. 15. This relation indicates that the maximum power coefficient occurs at the shift-angle $=45^{\circ}$. Thus, both the theoretical and experimental power coefficients are illustrated in Fig. 16, for different wind speeds within the range $(4.1 \leq V \leq 10 \mathrm{~m} / \mathrm{s})$ and the shift-angle $=45^{\circ}$. The values of the theoretical and experimental power coefficients of the prototype approximately have the same trend.

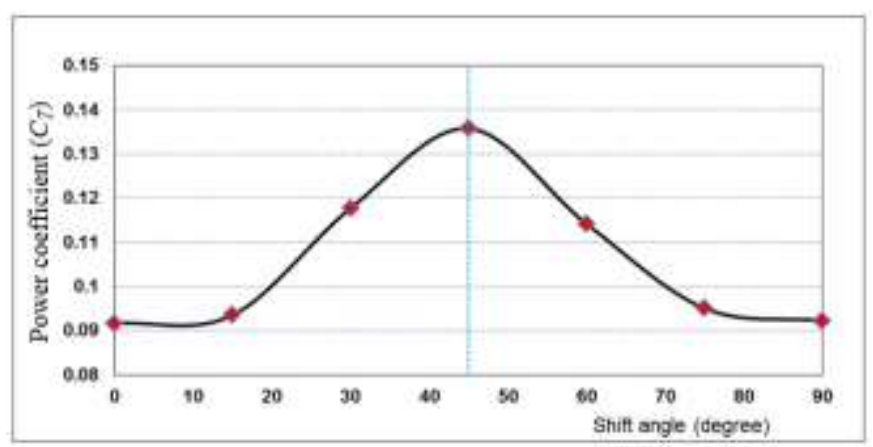

Fig. 15. Effect of shift-angle on experimental power coefficient

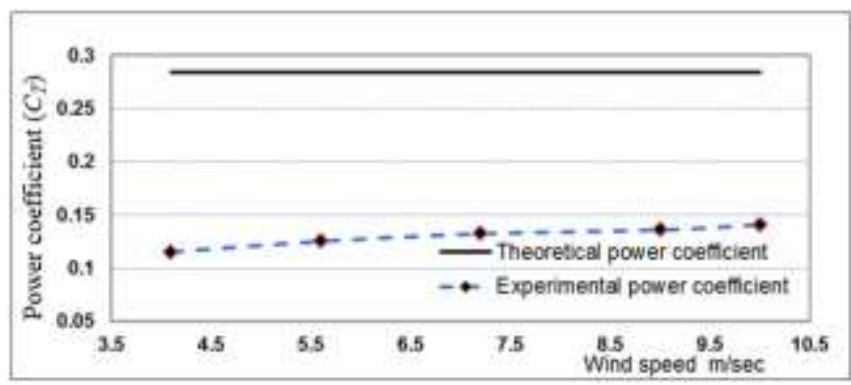

Fig. 16. The prototype power coefficients at different wind speeds

The theoretical natural frequencies of the prototype and mode shapes are evaluated. Furthermore, the equivalent experimental natural frequencies are presented by inspecting the measured frequency response. Two examples of the measured frequency response (which is the main parameter for assessing the required natural frequencies) in addition to the coherence function of the prototype using a volume percentage of $\mathrm{ZnO}$ equals $0.3 \%$ are shown in Fig. 17 and Fig. 18, respectively. Besides, the first four mode shapes of the prototype are shown in Fig. 19.

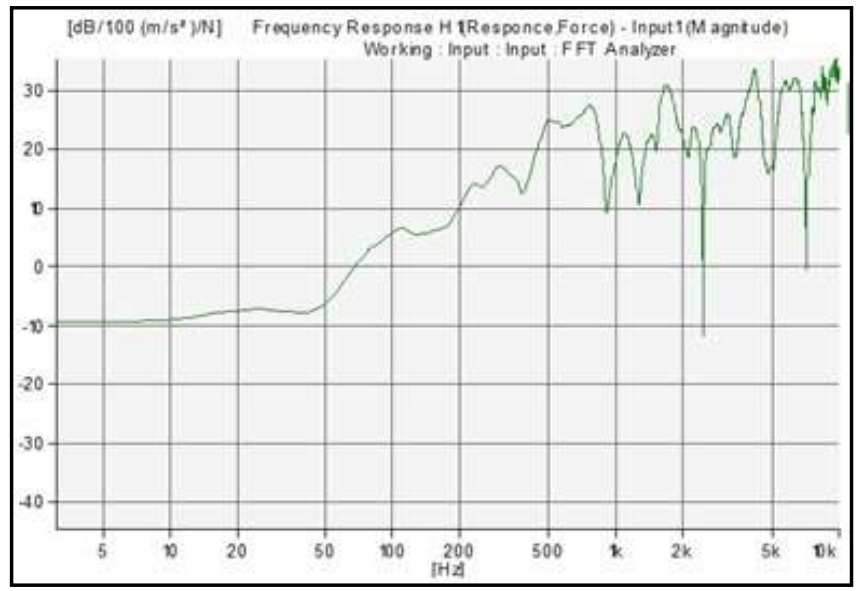

Fig. 17. Frequency response function using Vol $0.3 \% \mathrm{ZnO}$

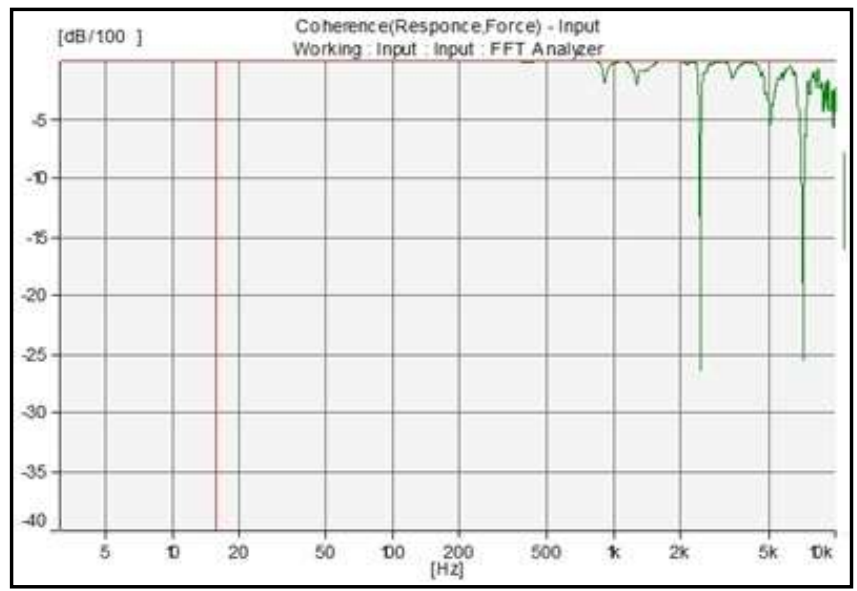

Fig. 18. Coherence function using $\mathrm{Vol} 0.3 \% \mathrm{ZnO}$ 


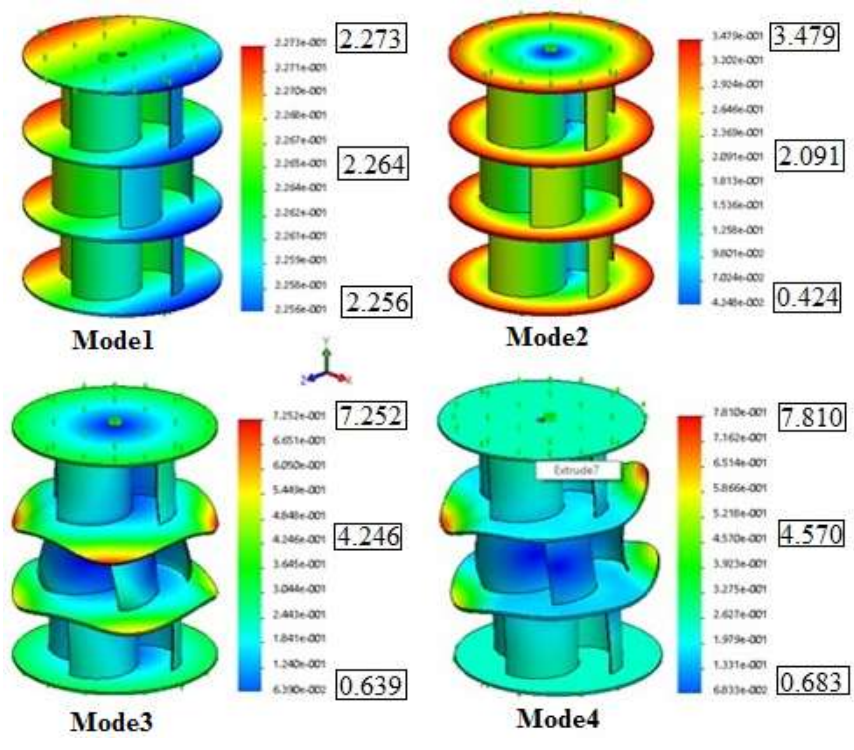

Fig. 19. The first four mode shape

Both the theoretical and the experimental natural frequencies of the model are presented in Fig. 20, with respect to different four mode shapes. The experimental prototype natural frequency values are similar to their equivalent theoretical ones for the first four-mode shapes. The value of natural frequencies increases when the value of the volume percentages of $\mathrm{ZnO}$ increases. Both the theoretical and experimental natural frequencies have high values, especially for the third and the fourth mode shapes. Therefore, the model can safely rotate with rotational speeds less than the values of these frequencies.

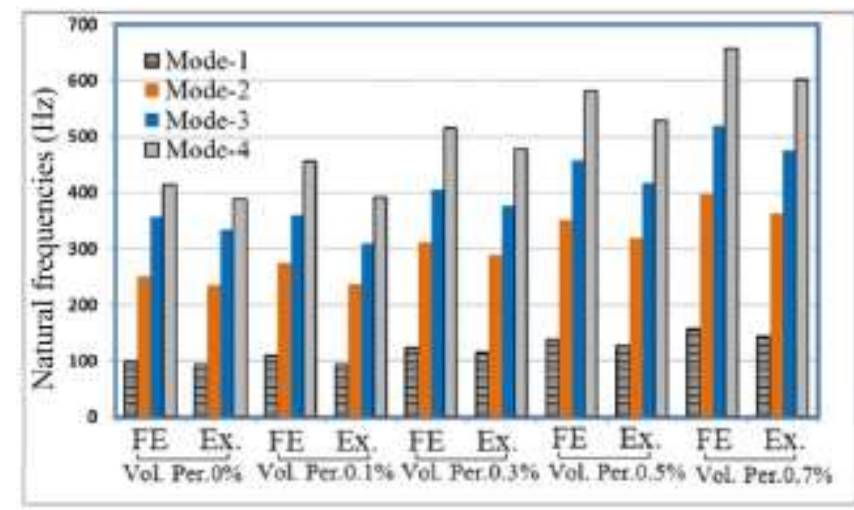

Fig. 20. Natural frequencies (Hz) at different volume percentages of $\mathrm{ZnO}$

\section{CONCLUSION}

This paper is mainly concerned with enhancing the blades' structure of a vertical axis wind turbine, which is appropriate for countries that have a reasonable wind speed. The blades' structure of this kind of turbines can be improved for increasing its durability through reinforcing its light composite blades using Zinc-Oxide nanoparticles. Moreover, the obtained results about epoxy/ZnO-NPs nanocomposites confirm the significant role of inorganic NPs, with a good degree of dispersion throughout the epoxy matrix, in the improvement of the mechanical performance of epoxy composites to be qualified for real-use applications.
A multistage (layers) of Savonius blades VAWT prototype is built for performing the necessary ultrasonic and vibration tests to assess the performance of the proposed design. Also, a simple theoretical model is presented to assess the theoretical power coefficient $\left(C_{T}\right)$ of this proposed VAWT. Moreover, the effect of the shift-angles between the blades' layers on experimental power coefficient $\left(C_{E x}\right)$ has been evaluated. The tests indicate that the maximum $\left(C_{E x}\right)$ of the VAWT which has three stages of blades occurs at shift-angle equal to $\left(45^{\circ}\right)$ of the middle stage related to the other stages. Furthermore, five different VAWT composite blades having five different $\mathrm{ZnO}$ volume percentages $(0 \%, 0.1 \%, 0.3 \%, 0.5 \%$, and $0.7 \%)$ are tested for assessing their values of the attenuation coefficient $(\zeta)$ and the phase velocity $\left(C_{p}\right)$ in addition to the dynamic Young's modulus $\left(E_{\mathrm{d}}\right)$.

The manufactured prototype has been used for measuring the experimental natural frequencies to compare it with the theoretical natural frequencies. The values of the experimental natural frequencies are found to be similar to their corresponding theoretical values for the first four mode shapes. Furthermore, the values of the experimental and theoretical natural frequencies have significantly high values, especially for the third and fourth mode shapes. Therefore, the proposed model can rotate with large rotational speeds lower than the values of the fourth mode shape's frequencies to avoid the resonance scenarios risks.

The results of this research reveal that the more the $\mathrm{ZnO}$ NPs, the better the performance of the composite blades VAWT. However, in real case scenarios, tradeoffs between the cost and performance have to be considered.

\section{REFERENCES}

[1] A. Fernández-Guillamón, K. Das, N. Cutululis, and Á. Molina-García, "Offshore wind power integration into future power systems: Overview and trends", Journal of Marine Science and Engineering, vol. 7, no. 11, 399, pp. 1-23, 2019.

[2] E. Oğuz, and A. Şentürk, "Selection of the most sustainable renewable energy system for Bozcaada Island: Wind vs. photovoltaic", Sustainability, vol. 11, no. 15, 4098, pp. 1-33, 2019.

[3] F. Moreira, A. Antunes, and M. De-Freitas, "Trends in wind-power desalination for water supply", Journal of Environmental Protection, vol. 10, no. 6, pp. 807-820, 2019.

[4] I. Ullah and M. Rasul, "Recent developments in solar thermal desalination technologies: A review", Energies, vol. 12, no. 1, 119, pp. 1-31, 2019.

[5] M. Eltawil, Z. Zhengming, and L. Yuan, "Renewable energy powered desalination systems: Technologies and economics-State of the art", Twelfth International Water Technology Conference, IWTC12-2008, Alexandria, Egypt, pp. 1-38, 2008.

[6] R. Ramkissoon, K. Manohar, and A. Adeyanju, "Small scale wind powered reverse osmosis plant without batteries in Trinidad and Tobago", International Journal of Engineering Trends and Technology (IJETT), vol. 58, no. 3, pp. 123-129, 2018.

[7] J. Kaldellis, "Social attitude towards wind energy applications in Greece", Energy Policy, vol. 33, pp. 595-602, 2005.

[8] G. Van Kuik, J. Nijssen, D. Lekou, J. Mann, J. Srensen, C. Ferreira, J. Wingerden, D. Schlipf, P. Gebraad, H. Polinder, A. Abrahamsen, G. Bussel, J. Sørensen, P. Tavner, C. Bottasso, M. Muskulus, D. Matha, H. Lindeboom, S. Degraer, O. Kramer, S. Lehnhoff, M. Sonnenschein, P. Sørensen, and R. Künneke, "Long-term research challenges in wind energy - A research agenda by the European Academy of Wind Energy", Wind Energy Science (EAWE), vol. 1, pp. 1-39, 2016.

[9] S. Qureshi, S. Danish, and M. Khalid, "A new method for extracting ocean wave energy utilizing the wave shoaling phenomenon", International Journal of Environmental and Ecological Engineering, vol. 4, no. 12, pp. $679-685,2010$. 
[10] S. Ahmad and R. Tahar, "Selection of renewable energy sources for sustainable development of electricity generation system using analytic hierarchy process: A case of Malaysia”, Renewable Energy, vol. 63, pp. 458-466, 2014.

[11] K. Khader and O. Nada, "Efficiency enhancement of sea waves energy converter via lean principles using an effective mechanical mechanism", Engineering Research Journal (ERJ), vol. 42, no. 1, pp. 1-9, 2019.

[12] M. Johari, M. Jalil, and M. Shariff, "Comparison of horizontal axis wind turbine (HAWT) and vertical axis wind turbine (VAWT)", International Journal of Engineering and Technology, vol. 7 (4.13), pp. 74-80, 2018.

[13] K. Pope, I. Dincer, and G. Naterer, "Energy and exergy efficiency comparison of horizontal and vertical axis wind turbines", Renewable Energy, vol. 35, no. 9, pp. 2102-2113, 2010.

[14] M. Saad and N. Asmuin, "Comparison of horizontal axis wind turbines and vertical axis wind turbines," IOSR Journal of Engineering (IOSRJEN), vol. 4, pp. 27-30, 2014.

[15] E. ElBeheiry, and W. El-Askary, "Performance assessment of a multi-step oscillating-blade vertical wind turbine", International Journal of Energy and Power, vol. 1, no. 1, pp. 18-25, 2012.

[16] E. ElBeheiry, and W. El-Askary, "A multi-step on-off blade vertical rotor for harnessing wind energy", In 2nd International Conference on Power and Energy System, Singapore, December 2012, pp. 12-19.

[17] L. Vita, U. Paulsen, and T. Pedersen, "A novel floating offshore wind turbine concept: New developments", In European Wind Energy Conference and Exhibition, Warsaw Poland, April 2010, pp. 1-10.

[18] U. Paulsen, H. Madsen, K. Kragh, P. Nielsen, I. Baran, J. Hattel, E. Ritchie, K. Leban, H. Svendsen, and P. Berthelsen, "DeepWind-from idea to $5 \mathrm{MW}$ concept", Energy Procedia, vol. 53, pp. 23-33, 2014.

[19] M. Saadat and P. Li, "Modeling and control of a novel compressed air energy storage system for offshore wind turbine", In 2012 American Control Conference, Montreal, Canada, June 2012, pp. 3032-3037.

[20] T. Sant, D. Buhagiar, and R. Farrugia, "Evaluating a new concept to integrate compressed air energy storage in spar-type floating offshore wind turbine structures", Ocean Engineering, vol. 166, pp. 232-241, 2018

[21] W. Tian, Z. Mao, B. Zhang, and Y. Li, "Shape optimization of a Savonius wind rotor with different convex and concave sides", Renewable Energy, vol. 117, pp. 287-299, 2018.

[22] A. Biadgo, A. Simonovic, D. Komarov, and S. Stupar, "Numerical and analytical investigation of vertical axis wind turbine", FME Transactions, vol. 41 , no. 1 , pp. $49-58,2013$.

[23] U. Saha and M. Rajkumar, "On the performance analysis of Savonius rotor with twisted blades", Renewable Energy, vol. 31, no. 11, pp. 17761788,2006

[24] A. Hossain, A. Rahman, M. Rahman, S. Hasan, and J. Hossen, "Prediction of power generation of small scale vertical axis wind turbine using fuzzy logic", Journal of Urban and Environmental Engineering, vol. 3, no. 2, pp. 43-51, 2009.

[25] L. Mitulet, G. Oprina, R. Chihaia, S. Nicolaie, A. Nedelcu, and M. Popescu, "Wind tunnel testing for a new experimental model of counterrotating wind turbine", Procedia Engineering, vol. 100, pp. 1141-1149, 2015.

[26] M. Torresi, F. Benedittis, B. Fortunato, and S. Camporeale, "Performance and flow field evaluation of a Savonius rotor tested in a wind tunnel", Energy Procedia, vol. 45, pp. 207-216, 2014.

[27] N. Mahmoud, A. El-Haroun, E. Wahba, and M Nasef, "An experimental study on improvement of Savonius rotor performance", Alexandria Engineering Journal, vol. 51, no. 1, pp. 19-25, 2012.

[28] A. Al-Faruk and A. Sharifian, "Geometrical optimization of a swirling Savonius wind turbine using an open jet wind tunnel", Alexandria Engineering Journal, vol. 55, no. 3, pp. 2055-2064, 2016.

[29] G. Hassan, A. Hassan, and M. Youssef, "Numerical investigation of medium range Re number aerodynamics characteristics for NACA0018 airfoil", CFD Letters, vol. 6, no. 4, pp. 175-187, 2014.

[30] K. Rogowski, and R. Maroński, "CFD computation of the Savonius rotor", Journal of Theoretical and Applied Mechanics, vol. 53, no. 1, pp. $37-45,2015$

[31] Y. Toparlar, B. Blocken, B. Maiheu, and G. Heijst, "CFD simulation of the near-neutral atmospheric boundary layer: New temperature inlet profile consistent with wall functions", Journal of Wind Engineering and Industrial Aerodynamics, vol. 191, pp. 91-102, 2019.

[32] Y. Zhong-Jia, G. Yi-Zhuo, L. Min, L. Yan-Xia, L. Jie, and Z. Zuo-Guang, "Design and analysis of small-scale lift-type vertical-axis wind turbine using composite blade", Polymers and Polymer Composites, vol. 22, no. 4, pp. 423-430, 2014.
[33] M. Hameed, S. Afaq, and F. Shahid, "Finite element analysis of a composite VAWT blade", Ocean Engineering, vol. 109, pp. 669-676, 2015

[34] J. Lin, Y. Xu, and Y. Xia, "Structural analysis of large-scale vertical axis wind turbines Part II: Fatigue and ultimate strength analyses", Energies, vol. 12, 2584, pp. 1-18, 2019

[35] P. Kumar, K. Sivalingam, T. Lim, S. Ramakrishna, and H. Wei, "Review on the evolution of Darrieus vertical axis wind turbine: Large wind turbines", Clean Technologies, vol. 1, no. 1, pp. 205-223, 2019.

[36] S. Mansour, "Study of thermal stabilization for polystyrene/carbon nanocomposites via TG/DSC techniques", Journal of Thermal Analysis and Calorimetry, vol. 112, pp. 579-583, 2013.

[37] W. A. El-Askary, A. S. Saad, A. M. AbdelSalam, and I. M. Sakr, "Experimental and theoretical studies for improving the performance of a modified shape Savonius wind turbine", Journal of Energy Resources Technology, vol. 142, no. 12, 121303, 2020.

[38] M. H. Mohamed, G. Janiga, E. Pap, and D. Thévenin "Optimization of Savonius turbines using an obstacle shielding the returning blade", Renewable Energy, vol. 35, no. 11, pp. 2618-2626, 2010.

[39] K. M. Khader and O. A. Nada, "Using crank-crank mechanism to reorient flat blades of vertical wind turbine for improving its performance", Alexandria Engineering Journal, 2020.

https://doi.org/10.1016/j.aej.2020.07.020, 2020

[40] C. Saravia, S. Machado, and V. Cortínez, "A composite beam finite element for multi-body dynamics: Application to large wind turbine modeling", Engineering Structures, vol. 56, pp. 1164-1176, 2013.

[41] M. Alonso-Martinez, J. Adam, F. Alvarez-Rabanal, and J. Díaz, "Wind turbine tower collapse due to flange failure: FEM and DOE analyses", Engineering Failure Analysis, vol. 104, pp. 932-949, 2019

[42] M. Shzu, M. Morais, Z. Del-Prado, and S. Avila, "Finite element analysis of a wind turbine tower with a pendulum tuned mass damper", Proceedings of the XVII International Symposium on Dynamic Problems of Mechanics, Natal, Brazil, pp. 1-8, 2015.

[43] S. Rao, Mechanical Vibrations, 5th Edition, Upper Saddle River: Prentice Hall, 2011.

[44] H. Mori, T. Norisuye, H. Nakanishi, and Q. Tran-Cong-Miyata, "Ultrasound attenuation and phase velocity of moderately concentrated silica suspensions", Ultrasonics, vol. 93, pp. 63-70, 2019.

[45] M. Shamsuzzaman, M. Khan, M. Bhuiyan, M. Rahman, M. Khan, D. Paul, and D. Sarkar, "Attenuation property of wood and fiber reinforced polymer composite materials for neutron and gamma radiation shielding", American Journal of Materials Science, vol. 9, no. 1, pp. 8-14, 2019.

[46] J. Zhang, K. Dai, X. Wang, D. Yu, B. Yang, H. Zhang, and Z. You, "Improved energy absorption characteristics based on elastic polymermodified porous material for multiple extreme mechanical impacts", Applied Sciences, vol. 10, 110, pp. 1-19, 2020.

[47] V. Rajendran, A. Devi, M. Azooz, and F. El-Batal, "Physicochemical studies of phosphate based $\mathrm{P}_{2} \mathrm{O}_{5}-\mathrm{Na}_{2} \mathrm{O}-\mathrm{CaO}-\mathrm{TiO}_{2}$ glasses for biomedical applications", Journal of Non-Crystalline Solids, vol. 535, pp. 77-84, 2007

[48] S. Ghoneam, A. Hamada, and M. El-Elamy, "Experimental and analytical investigations of the dynamic analysis of adhesively bonded joints for composite structures", Solid State Phenomena, vol. 147-149, pp. 663$675,2009$.

[49] H. Farha, S. Mansour, and M. Kotkata, "Structural, optical, and magnetic study of dilute magnetic semiconducting Co-doped $\mathrm{ZnO}$ nanocrystals synthesized using polymer-pyrolysis route", Journal of Material Science, vol. 51, pp. 9855-9864, 2016

[50] S. Mansour, H. Farha, and M. Kotkata, "Synthesis and study of $\mathrm{ZnO}$ nanoparticles by polymer pyrolysis route using two different polymerization initiators", Journal of Applied Ceramic Technology, vol. 14, pp. 1213-1221, 2017.

[51] S. Maensiri, P. Laokul, and S. Phokha, "A simple synthesis and magnetic behavior of nanocrystalline $\mathrm{Zn}_{0.9} \mathrm{Co}_{0.1} \mathrm{O}$ powders by busing $\mathrm{Zn}$ and $\mathrm{Co}$ acetates and polyvinyl pyrrolidone as precursors", Journal of Magnetism and Magnetic Materials, vol. 305, pp. 381-387, 2006.

[52] S. Mansour, A. Elsad, and M. Izzularab, "Dielectric properties enhancement of PVC nanodielectrics based on synthesized $\mathrm{ZnO}$ nanoparticles", Journal of Polymer Research, vol. 23, no. 85, pp. 1-8, 2016.

[53] SolidWorks, "Installation and administration SolidWorks 2017", 2017, http://docplayer.org/69170433-Installation-und-administrationsolidworks-2017.html 
Title Arabic:

$$
\begin{aligned}
& \text { تحسين الأداء الديناميكي لتوربينات الرياح العمودية باستخدام }
\end{aligned}
$$

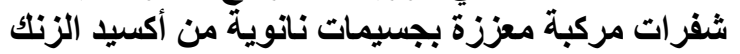

\section{Arabic Abstract:}

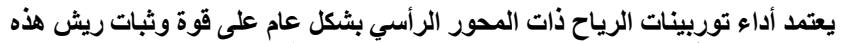

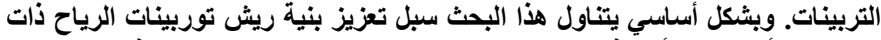

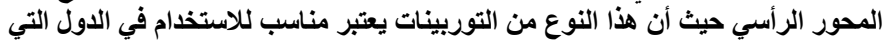

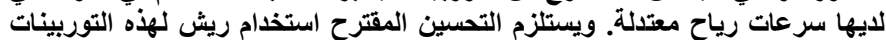
مصنعة من مواد مركبة خفيفة ومعززة باستخدام جزيئات نانوية من أكسيد الزنك يتم التهات
تصنيعها عن طريق الاححلال الحراري للبوليمر ـولتقييم أداء التصميم المقترح، تم تصميم

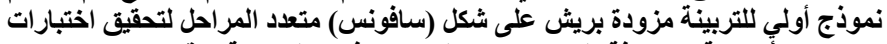

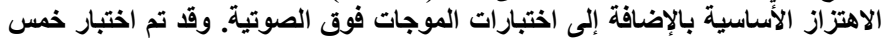

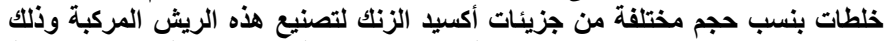

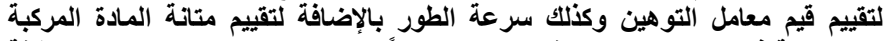

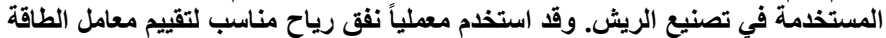

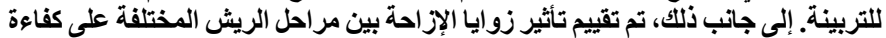

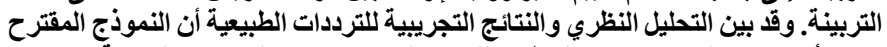

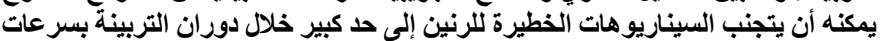
دوران عالية. 